\title{
PLASTIC OPERATIONS
}

ON THE

\section{NECK AND ARMS FOR SEVERE CICATRICIAL DEFORMITIES AF'TER BURNS.}

BY

JOHN CROFT.

Received March 7th-Read May 14th, 1889.

I HAVE limited the scope of my paper to plastic operations on the neck and arms, and to operations for the relief of severe deformities from the effects of burns, because I hope to limit discussion to a particular mode of transplanting skin flaps in such cases. The treatment adopted in the five cases about to be narrated is not unlikely to raise discussion on the whole subject of the surgical treatment, operative and instrumental, of such deformities as those referred to in the title of the paper, but I should be well pleased if this preliminary observation has the effect of limiting any discussion which may arise to the exclusive use of plastic surgery for the relief of extensive contractions and deformities after burns. I do not pretend in this short communication to review the respective advantages of noninstrumental and instrumental treatment. I have not had any experience in the employment of instrumental or ortho- 
pædic apparatus for such severe deformities as those my patients were suffering from, and therefore I do not offer any observations on the subject. My particular object is to advocate the use of large flaps transplanted in two stages or by two separate operations.

The history of this mode of procedure appears to be one of gradual advance from small beginnings. Sir William Mac Cormac in his address on plastic surgery to the Midland Medical Society in 1888 referred to this plan of raising bridge-like flaps to be transplanted in two stages, but gave no historical account of it, and I believe that I am right in saying that he had not, and that he has not succeeded in tracing it to any historical origin.

For my own part I first made acquaintance with it in 1880, when I took under my care in St. Thomas's Hospital a boy who was the subject of severe "talipes calcaneus" caused by the contraction of a burn-scar on the front of the leg, ankle, and foot. When thinking of the best way to relieve this condition, I was reminded by Sir William, then Mr. Mac Cormac, of the successful use of bridge-like flaps in closing up " ectopia vesicæ." I determined to adapt the plan to the case before me. I failed to find any reference to this mode of transplanting in any works of reference, and in proportioning my flaps I felt compelled to proceed experimentally. I decided to begin by making the flap not more than three times longer than the width of its attachment. Casts and drawings of this case were shown.

The case turned out very successfully, and I published an account of it in the 'Med. Times and Gaz.' for November 17 th, 1883, after the operation had stood the test of quite two years' wear and tear. In my remarks on the case at that time I gave the opinion that " the length of the straps should not be much, if any, more than three times the width."

Nearly two years elapsed before I again had an opportunity of putting this plan of transplanting into practice.

At the beginning of 1882 a young woman was put under my care for the relief of a severe contraction of the side of 
the neck caused by a burn in childhood. I determined in this case to proceed on the same lines as before, and in this Sir William Mac Cormac concurred with me. In this case and four subsequent ones I raised flaps eight to nine inches long by two and a half inches to three inches wide. This is what I mean by raising flaps on a large scale. Later in the same year (1882) Sir William Mac Cormac treated a case in St. Thomas's in a similar manner, but did not use such large flaps.

I may say here that I have consulted all the recent systematic works on surgery, and failed to find anything more than a brief reference to this mode of transplanting skin, and I have not discovered any instructions on the subject beyond those included in Sir William Mac Cormac's paper already referred to.

I believe that it will be now a convenient mode of presenting the subject if I give a general account of the mode of operating in the five cases on which this paper is founded, then to give a brief narrative of each case, and, lastly, the conclusions and criticisms which I have ventured to draw up.

Mode of operating.-The strap or bridge of skin to be raised was in my cases cut where it could be taken free of scar tissue and well supplied with blood, yet sufficiently near for twisting into its bed. For the neck, the skin to be transplanted was taken from the back of the neck and shoulder, and measured eight and a half to nine inches in length, or sufficiently long to cross the median line of the neck.

In the arm similar measures were taken, and the bridge raised in a similar manner. These bridges were cut as thick as possible, especially in their central parts. The bleeding from the flap and wound was carefully arrested before dressings were applied.

The sides of the wound were approximated by sutures, but tension from them was avoided as much as possible. With the object of promoting approximation or preventing retraction of the edges, these were also sutured to the muscle and fascia near the centre of the gaping wound. 
This fixation of the edges was of assistance in limiting the extent of surface which was to heal by granulation.

The strap or bridge was left attached at each end.

The under surface and edges of the bridge are to become covered by granulations, and the whole to become charged with plastic material, and to remain abundantly vascular. This condition is to be promoted, and measures taken to ensure it.

The bridge must be prevented from re-uniting, and great care has to be taken that granulations do not spring up in the angles formed between the pedicles and the raw surface. In that situation there is not a little risk that the length of the span may become insidiously shortened.

Dressing. - I made use of oiled silk protective, dipped in carbolised oil, to insert between the raised skin and parts beneath it, carefully drawing it under the pedicles. This made an excellent dressing for this part, as it prevented any other dressings from sticking to the raw surface. The flap and wound were then covered in by antiseptic oiled dressings and salicylic wool. These were lightly but securely bandaged on, and in such manner as at the same time to keep the most movable part-as the head and neck or arm-in a fixed posture. There was some difficulty in keeping the long narrow bridge of skin from swaying and festooning.

In the fifth case, that of a rather restless child aged nine years, I experienced a great trouble from the mobility of the strap of skin. Partly owing to the movements of her head and neck, the centre of the strap showed signs of impaired nutrition. It began to ulcerate and to narrow and thin. This was stopped by applying a rigid apparatus to the trunk and head and neck, but irreparable injury had been done to the flap, and I would strongly advise anyone operating on a similar case in the young to apply an apparatus at the time of the first operation. In operating on the arm, for the first stage, in the adult, I have not needed any fixed apparatus, but I think it would be better to use it in the young. 
If all goes well and no complication occurs, in a fortnight or three weeks' time it will be safe to proceed to the next stage of the operation, viz. that of cutting across the contracted scar and transplanting the strip of skin. In judging of the right moment for beginning this second stage, the condition and extent of the granulating wound must be taken into account, with the fresh loss of blood which must ensue in making a bed for the transplant, the extent of this fresh wound, and the influence that these will have upon the vitality and vascularity of the transplant, which must now depend on one pedicle instead of two. When the operator thinks that the strength of his patient is quite equal to the occasion, he may proceed, but if he is in doubt he should wait a little longer.

At this second operation it is better first to cut through the contracted scar, and afterwards to cut across one end of the bridge. In dealing with the scar I have not sacrificed any tissue. I have been particular to cut down through scar tissue until I reached healthy fat or fascia or muscle. I need not say that all bleeding should have ceased before the final fixation of the transplant.

The bed and the transplant must be made to agree in length and for the most part in width, but the shape of the fresh wound cannot always be made to correspond exactly with the shape and extent of the transplant.

The form of this bridge has now considerably changed from what it was when it was first cut. It has become shorter and narrower, somewhat like the string of a bow. It has, however, become thicker from the quantity of plastic matter with which it is loaded.

In the neck and upper arm cases, the distal end of the flap was the one to be cut across, in the lower arm the proximal end was the one to be severed. The act of severance is always attended by a certain amount of local shock which should be allowed for.

Next the strap should be to a certain extent trimmed. The edges and granulating under surface at the free end, for a distance of nearly or quite half the length of the strap, voL. LXXII. 
should be pared or freshened, so that they shall present raw surfaces for primary union. In no case did the transplant correspond in its uniform width to the width of the bed for it. This always varied except at the part which was to receive the free half or third of the transplant.

It is enough to obtain primary union between the free end of the strap and the fresh wound. This union anchors the strap and fixes it in its place. Union along the rest of the extent of the transplant is only a work of time. The healing by granulation is not slow. At first the transplant looks very ungainly and unsightly and unpromising. As week after week goes by and healing takes place, the sausage-like thing flattens down and spreads out, until finally it may become twice as wide as it was originally cut.

The part of the transplant which causes anxiety is the distal inch of it. This may slough to a slight extent, and union may therefore fail to take place. In consequence of this the strap may retract from its holding. It must be then kept in place by strapping, and this is a troublesome process. Moreover, a vertical or longitudinal scar may be the result at that spot, and in the neck a vertical or longitudinal scar is to be particularly avoided. It is more necessary to avoid failure of terminal union in the neck than in the arm. A median vertical scar in the neck is a great blot on the success of the case ; that scar may contract or at least it may prevent stretching there. It will stand out as a frænum. The present condition of the girl Emma Willustrates this.

In each of the two completed cases of operation on the neck I had to resort to a third operation, in order to neutralise the consequence of having allowed a vertical scar to form in the front of the neck. I raised a tlap of suitable proportions from the chest and turned it upwards into the front of the neck at one and the same operation in each case. This has improved the state of things in that situation. In the third case the deformity is still under treatment. Although I point out the evil I must confess that 
in indicating the remedy $I$ am not confident that it will always prove infallible.

I would suggest that the strap or bridge should be made of the same large proportions, but to spring from lower down the slope of the neck, and to extend lower down on to the front or back of the shoulder. This would enable the operator to bring the end of the transplant further across the front of the neck and as far as the opposite side of it.

After the granulating sores have all finally healed the surgeon must wait patiently for about six months before the full effect of the proceeding will be fit for judgment.

\section{Results.}

First case (contracted neck case).-It is now six years and five months since this case finally left the hospital. Though the drag upon the mouth and ear is still slightly perceptible, her appearance has been greatly improved. The movements of the head and neck and shoulder are fairly free. The portions of skin transplanted are far wider than when she left the hospital, and yet they are soft, elastic, and free from any vicious change. She has been able to earn her living as a dressmaker until, just recently, a temporary illness has thrown her out of employment.

Second case (contracted arm case).- She left the hospital in February, 1885, and therefore upwards of four years and three months have elapsed since she was under treatment. She is most grateful for the benefits she derived from the operations. She can extend her arm freely, and can carry heavy weights. The flaps and scars continue sound. Lastly, but of first importance, she has married.

The third and fourth cases (contracted neck and arm in one person). She left the hospital in October, 1887, and therefore one year and seven months have elapsed since she left. The flap transplanted into the neck is seen to form a wide, soft, elastic side to the neck. There is no dragging 
on the side of the face and chin. The personal appearance has greatly improved. The arm is in an equally satisfactory condition. The subject of these operations is now training to become a nurse. Had not the condition of the neck, and particularly that of the arm, been greatly improved she would not have been accepted as a probationer. She had set her heart on becoming a nurse.

Fifth case (neck case). - The treatment of this child has not yet been finished. It was a very bad case, as the photographs show. The dragging on the features on the right side had produced very considerable deformity. This deformity had been much diminished, and we are justified in expecting still further improvements.

\section{Conclusions.}

The advantages claimed for this plan of operating are :

I. That risks of sloughing of any part (edges or free ends) are greatly diminished. The transplantation being made two or three weeks after the first operation, the local effects of shock are avoided or reduced to a minimum, viz. only that attending the severance of the pedicle.

II. That instead of being transplanted when recently drained of blood and reduced in temperature it is moved when abundantly vascular and full of active living plastic matter.

These advantages, which enable the operator to proceed with confidence and deliberation, are to be set against the longer time during which the patient remains under treatment.

When the flap is raised and the scar operated on at the same sitting the healing by primary union and by granulation goes on concurrently. When the proceedings are separated by three weeks' interval, the duration of treatment is somewhat prolonged. However, this is amply compensated for by the advantages already mentioned.

III. The practice adopted in the cases narrated has 
manifest advantages over the plan of transplanting flaps from a distant part of the body. The forearm is a convenient region from which to transfer skin to the neck, but it is obviously not available for such large flaps as those required for the cases under consideration.

When seeking for smaller transplants to the neck, for iustance, for such a piece of skin as that required in Case 5 (the incomplete case) we might adopt the plan of shifting a piece from the abdomen to the forearm and thence to the neck. This would be an adaptation of a plan suggested by Dr. Shrady, of New York, and mentioned in Sir William Mac Cormac's address on plastic surgery already quoted.

The patients on whom the operations had been performed were all exhibited to the Society, and photographs were also shown.

CASE 1.-Rose G-, æt. 19 years, admitted October 17th, 1881. Burnt by fire when a child, badly, on right side of neck and on right arm.

On admission she presented a cicatricial contraction on the right side of the neck, extending from the level of the lower jaw to the clavicle. A band or fold was formed by the contraction; this band was an inch and a half in width, and overlapped to this extent anteriorly. The lobe of the ear was effaced, and the corner of the mouth was drawn down with part of the lower lip. The outline of the jaw was not visible, and the head on this side was dragged over towards the shoulder, the movements being restricted (see Figs. 1, 2, and 3).

January 14th, 1882.-First operation. A strap of skin was raised from the back of the neck and shoulder; it extended from the level of the seventh cervical vertebra to near the posterior fold of the axilla. It was nearly nine inches in length, and about two and a half inches in width. It was left attached at both ends. The edges of the skin wound were approximated as nearly as possible by sutures. The strap was wrapped in oiled silk protective, and the whole dressed with lint soaked in warm oil 
and terebene. No rigid apparatus was put on to prevent movements of the head and neck, but the arm and head were bandaged into position.

On February 18th, or thirty-fourth day, the second stage of the operation was performed. As the patient's health had been slow to rally from the first operation, this long period had to be allowed before the second stage was undertaken.

An incision was carried completely across the side of the neck, nearer the jaw than the clavicle, and the edges of the skin were raised so as to form fringes about one inch

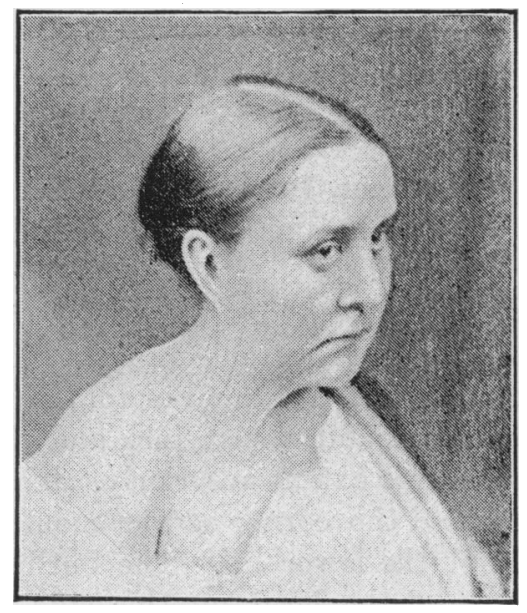

Fra. 1.-R. G- before any operation.

in depth. The axillary end of the strap was cut across, and the flap transplanted on to the neck. The free end and upper edge were carefully sutured into position, and about one third of the lower edge was fixed by sutures. A transverse incision was made above the right mammary region to relieve tension.

The length of the flap transplanted was not so long as it should have been, but was as long as the width of its basal attachment warranted. The free end of this flap died to 
the extent of nearly an inch, and in consequence of this the whole flap began to contract and retract, and had it not been for some union along the upper edge of the flap a failure might have ensued. By strapping and bandaging, the union was increased and strengthened until the transplant had wholly united.

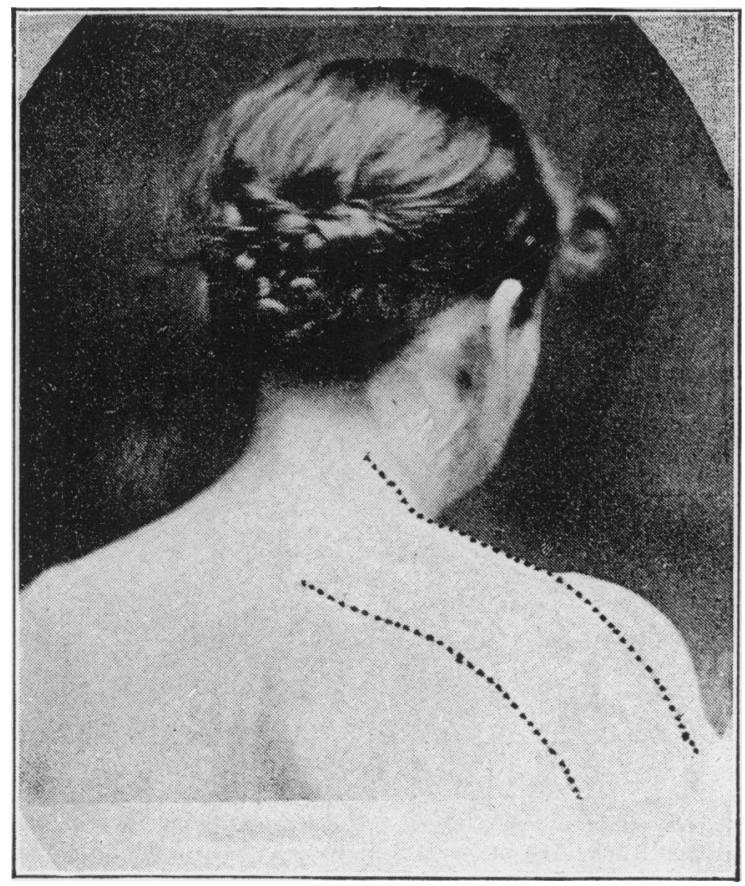

Fia. 2.-R. G- five years after operations. The dotted lines show the situation and extent of the strap of skin which was raised and transplanted.

A vertical scar was left to the right of the median line of the neck, and here the contraction was still considerable, partly owing to the unrelieved original deformity, and partly to the rigidity of the vertical scar.

She was sent out on the 26th May, a little over three 
months after the second operation, with directions to return in a few days for another plastic operation.

She was readmitted, and a month later I undertook another operation to relieve the contraction in the front of the neck. I proposed to do this by raising a bridge of skin from the chest, and by transplanting the flap on to

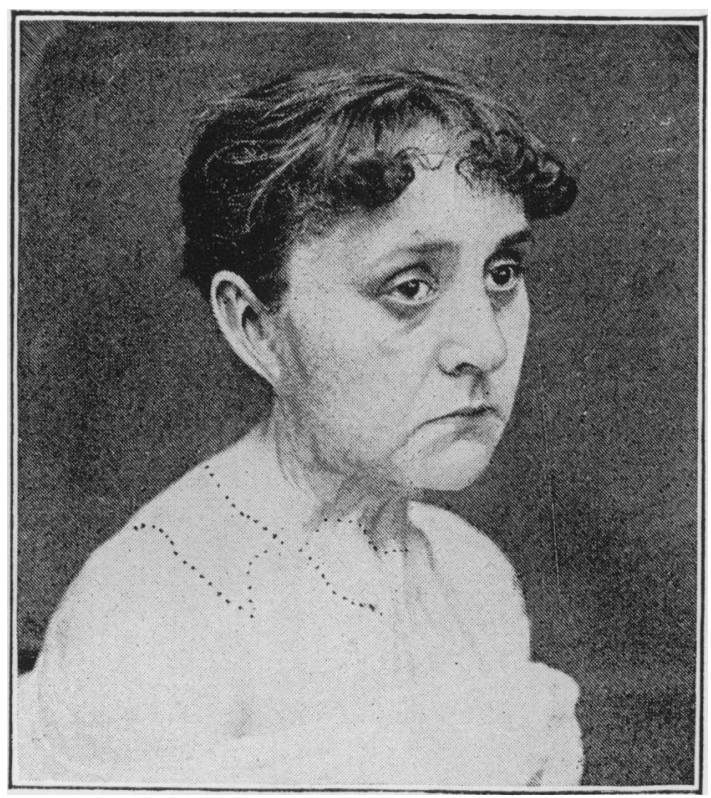

FIG. 3.-R, G - five years after operation. Shows the greatly improved appearance of patient. The dotted lines show the situation into which the first trausplant settled, and the same of the second transplant.

the front of the neck. This bridge was about six inches long and two inches wide, and extended from near the top of the sternum outwards and slightly downwards towards the axilla. Its lower edge skirted the mamma. It was dressed after the mode already described.

On the fifteenth day after this step I made the second. An incision was made across the contraction at the lower part of the neck, horizontally outwards from the upper 
angle of the wound as far as and beyond the end of the first transplant, so that the end of the new flap might underlap the end of the first one. Then the axillary end of the bridge was cut through and the flap sutured into place. This united primarily wherever its edges came well into contact, and the rest healed by granulation.

By the 8th December the sore from which the transplant had been made had healed over, and the flap had settled into its place. She then left the hospital.

The results of these operations may be judged of by the results as seen in her own person at present and by the photos. The permanent improvement in her appearance is decided. The four operations had been spread over nearly fifteen months.

Case 2. Sarah Ann C-, æt. 40, single, admitted March 13th, 1884. When five years of age she fell into the fire and burnt the left side of chest, the upper and forearm badly, and several other parts, but not so badly. The healing occupied six months.

She was admitted into St. Thomas's Hospital under my care for badly contracted cicatrices on the left side at the date above mentioned. The upper arm on its aspect towards the axilla and side of chest was strongly webbed to those parts, and the forearm was drawn to a right angle with the upper arm by the extension of the web down the inner side and front of the elbow (see Figs. 7 and 8). The photograph shows the extent and severity of the webbing.

The scar itself extended from the right side of the sternum across the chest and axillary fold to the upper arm and along the inner side and front of the upper arm, elbow, and forearm to the wrist, where it ended by adhesion over the tendon of the flexor carpi ulnaris.

The web was thick and cordy at its free edges. At the elbow it measured about two and a half inches from its edge to its base.

The deformity on the right side was not so bad as to warrant any surgical interference, but the condition of the left 
arm had caused her to seek relief in operation. I explained the tedious and painful nature of the procedure. Nevertheless she determined to submit to it.

On April 26th I raised a bridge of skin from the outer

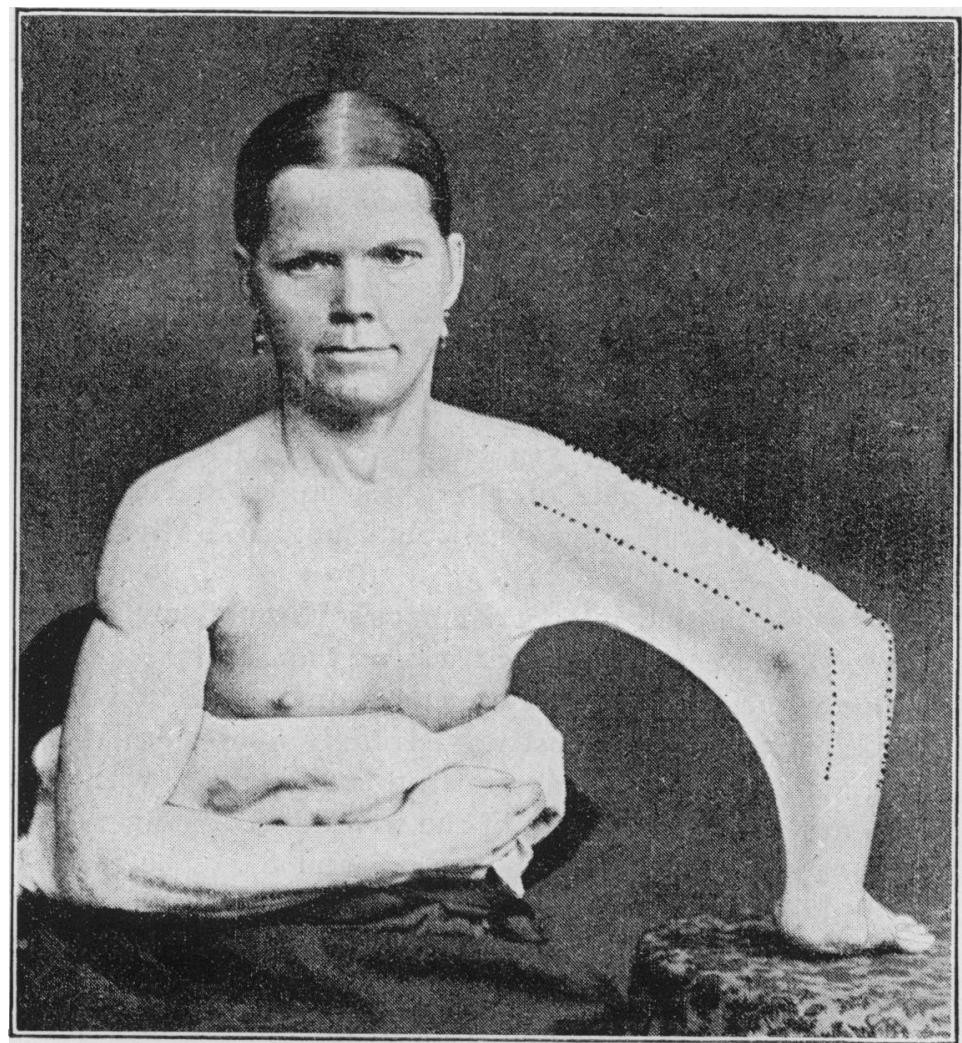

Fiq. 7.-S. A. C- before operations, March, 1884. The web is well shown. The dotted lines indicate where the straps of skin were raised and their extent.

side of the shoulder and upper arm, fully eight inches in length and two and a quarter inches in width, measuring from just below the point of the acromion. This bridge 
SEVERE CICATRICIAL DEFORMITIES AFTER BURNS. 363

was a good substantial one. It was dressed in the usual manner, and the arm bandaged to the side. Owing to the length of the bridge and the recumbent position of the patient, there was a great tendency on the central part of the bridge to drop backwards. This part of the flap was therefore kept slung.

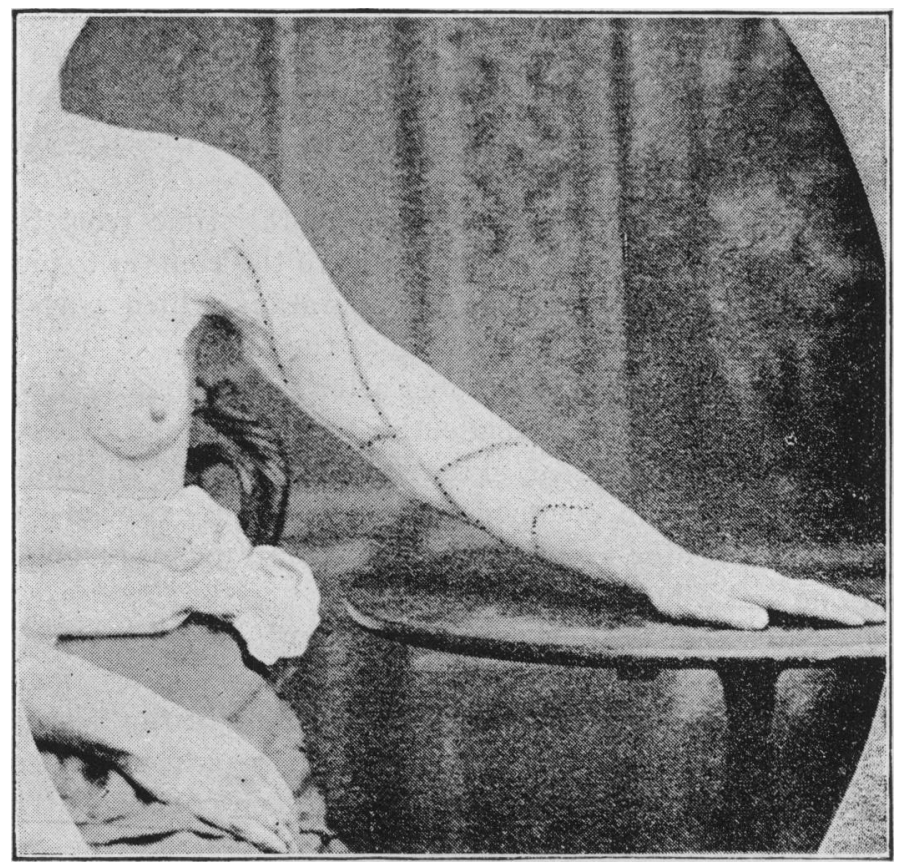

Fig. 8.-S. A. C-. This shows the greatly improved condition of the whole arm. The dotted lines show the situations into which the transplants have settled.

On May 12th, or the sixteenth day, the second stage of the operation was performed. An incision was commenced at the upper end of the anterior edge of the bridge and carried downwards and inwards across the web to the inner side of the elbow. This left a wide long wound. The lower end of the bridge was cut across (sufficiently low down 
to give a long enough flap) and the flap was then transplanted. The free end and the upper edge of the flap were sutured carefully into place. Dressings as usual.

The anterior edge and end of the flap did not unite well, but little sloughs formed where the cicatricial tissue had been included, and the flap therefore threatened to slip from its position. Such spots of union as did happen, however, just served to anchor the flap, but plaster had to be used to assist in keeping the flap in its place. In a month's time the flap had united throughout its length and breadth, and the sore on the outer side of the arm had made good progress.

On August 7th, or about three months' time from the operation, she was well, and was sent to the country to pick up strength and spirit for the operation which was to relieve the contraction remaining at the elbow.

She was readmitted in October after the autumn holiday, and on October 25th I made the first step in the lower operation. A bridge of skin was raised from the outer side of the forearm, commencing above at the external condyle. This bridge measured five and a half inches in length and one and a half inches in breadth.

On November 8th, or on the fourteenth day, it was safe to proceed with the transplanting. An incision was made transversely across the web about the middle of the forearm (or just below it) and the upper edge of the scar was raised into a fringe. A wide wound was the consequence. The upper end of the bridge was now cut across, and the flap was turned downwards and across the forearm until its free end could be brought into contact by suture with the skin at the inner border of the forearm. These sutures and the others along the lower edge of the flap secured the flap in place. In due course good union took place.

As soon as the condition of the sore and scar on the arm allowed of it, an extension apparatus was fitted to the limb, and the elbow was gradually opened out until she could keep her arm in an almost perfectly extended position.

She left the hospital on February 21st, 1885, after less 
than a year's treatment, in excellent health and spirits considering what she had gone through.

The photograph taken May 14th, 1885, shows very well the very improved state of the limb.

CASE 3.-Emily H-, æt. 22, admitted into St. Thomas's Hospital April 1st, 1886. She had been badly burnt by fire about the face, neck, and left arm when three years of age.

On admission she presented numerous superficial scars over the upper part of the face above the level of the mouth, but no deformity from contraction there. The lower part of the face, particularly the lower lip and chin, were very scarred and deformed. The line of junction of the mucous membrane with the skin of the lip was drawn down nearly to the chin, so that the red of the lip was everted and unsightly. The lips could be approximated when she made a determined effort to close the mouth, but ordinarily the lips did not meet, and left the teeth slightly exposed. The scarred skin of the chin was firmly drawn down towards the neck. The left angle of the mouth was tightly drawn downwards and outwards. The right side of the face was not so badly drawn (see Figs. 4, 5, and 6). There was not any dribbling from the mouth.

The left side of the neck presented the worst scarring and contraction. The chief contraction had occurred in the direction of a line from the angle of the mouth downwards and outwards to the middle of the clavicle. Here the scar was dense, and drawn into a frænum or fold about an inch and a half in depth. The scar extended, downwards over the clavicle, outwards to a line drawn from the angle of the jaw to the outer third of the clavicle, and inwards across the front of the neck to far round on the right side.

The head could not be bent over towards the right shoulder, and rotation towards the left side increased the deformity.

Left arm : There was a strong hard band in front of the elbow, which bound the forearm to the upper arm, so that it could not be extended much beyond a right angle. 
She was anxious to have something done for each deformity. I explained that more than one operation would be required for the neck and for the arm respectively, and that she would have to remain under treatment for a long period, probably a year. She determined to submit to the ordeal. She was in good health and fresh from the country.

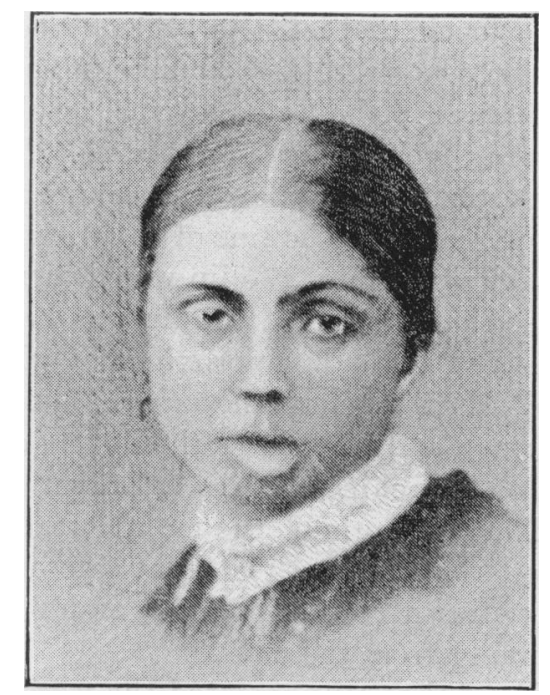

FiG. 4. - E. H - before operation. From an old photograph. Shows how the lip was drawn down and everted and that the shoulder was drawn up.

On April 19th, 1886, the first stage of the operation on the neck was performed. A strap of skin was raised from the neck and shoulder. It measured nine inches in length and three inches in width, and extended from below the level of the mastoid process downwards and outwards to beyond the acromion and outer fourth of the clavicle. The bridge was dressed with oiled silk protective, warm carbolised oil, and salicylic wool. Bandages were applied, and the arm was confined to the side, but no rigid apparatus was applied. The wounds were treated in the usual manner, but the strap was unfortunately allowed to re- 
unite to a slight extent at each end, and when the time came for transplanting the bridge was shorter by one inch than it was when first cut.

On the nineteenth day the second stage of the operation was undertaken. A long semilunar incision was made

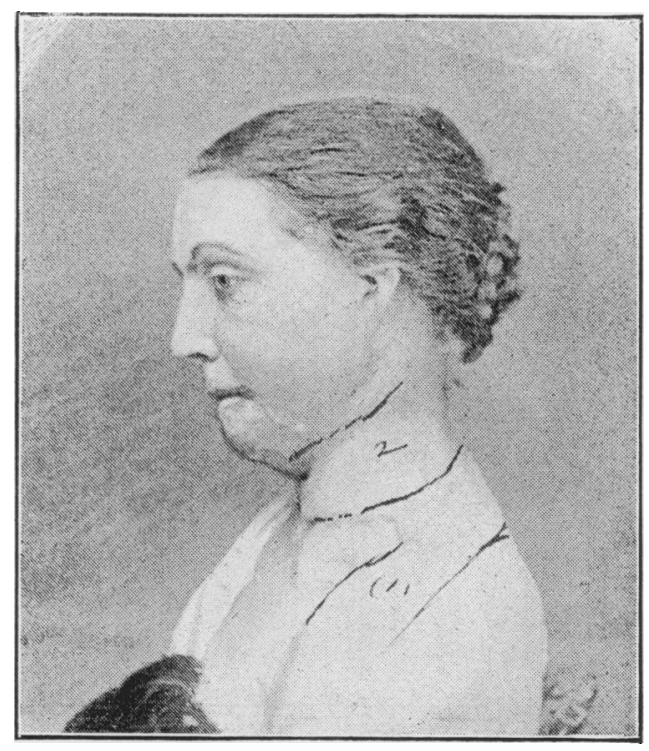

Fig. 5. -E. H- after operations. The dotted lines show (1) the situation from which the strap was transplanted, and (2) the long broad transplant in its new position. The improvements in the face and its expression are also apparent.

across the scar on the left side of the neck to the limits of the scar on the right side. The wound bled freely. The external jugular vein was divided. The edges of the scar were dissected up above and below until they formed fringes an inch in depth. Next, the lower end of the bridge was dissected up for an inch, and then cut across, the granulating edges and under surface were pared for about one half the length of the flap, and the long sausage-shaped thing. was transplanted into the wound. The end and upper edge were carefully sutured into position, and the 
lower edge for a short distance was also fixed by sutures. The remaining two thirds of this lower edge were unattached on account of the great width of the wound at the corresponding part of the side of the neck.

A stranger to this mode of operating would have been

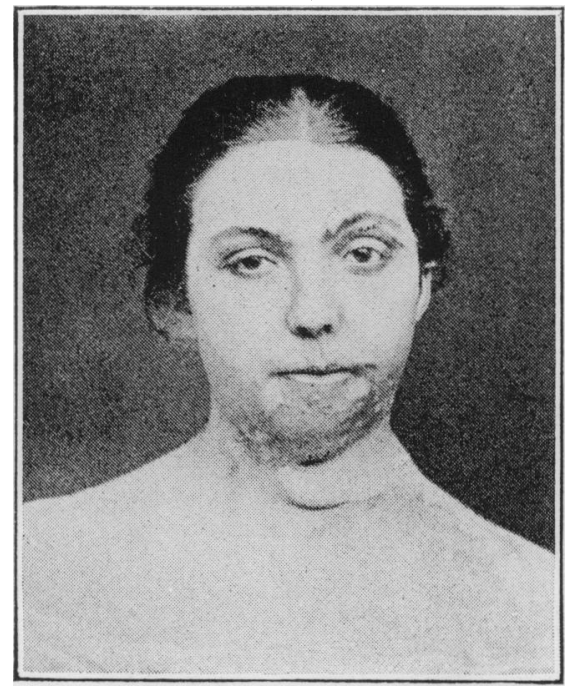

FIG. 6.-This shows the same as fig. 5. The improvements are more apparent.

very disappointed at the appearance of the parts at the completion of this operation, as the transplant looked so thick, clumsy, and narrow, and a considerable part of the fresh wound remained uncovered by flap.

Union followed nearly all along the upper edge of the flap, but the extreme end of it, which had been freshly dissected up (for reasons already stated) sloughed, and there, of course, union failed. However, the lower edge united well where it had been sutured. No retraction took place, and the flap kept its position satisfactorily. The rest of the flap healed and united readily, and by the eightieth day that part of the neck had healed over. By 
that time the transplant had flattened down and regained its normal width, and it promised to spread still wider.

She was now sent away into the country to recruit her strength.

On the 20th March, 1887, she was readmitted. Her appearance had already greatly improved. All contraction on that side had disappeared. The transplant formed a wide, soft, flexible covering to the left side of the neck.

On the right side there was an ugly piece of scar where the end of the flap had sloughed, and the gap had been filled up by granulation and cicatrisation. This scar, together with the original contraction, prevented the lip from coming up into its place, and the angle of the mouth on the right side was still slightly drawn down.

On April 16th, 1887, another and smaller operation was performed with the object of relieving the traction on the lower lip and right angle of the mouth.

The scar was divided deeply by a horizontal incision, and the edges dissected up into fringes, and then a flap of three inches by two was raised from the posterior inferior angle of the neck. This was immediately inserted. It united readily and completely, and fulfilled our intentions satisfactorily.

Thirty-six days after this operation she again left for the country.

There remained the arm contraction to be relieved. She was so well satisfied with the results of the operations on her neck that she determined to return to us in the summer that the arm might be operated on.

She was readmitted on June 14th of the same year (1887). The web in front of the elbow extended from the middle of the upper arm along its inner side and front as far as the wrist and base of the thumb. This bound the forearm to the upper arm at an angle of $97^{\circ}$; opposite the elbow it measured about three inches and a quarter in depth from its free edge. The scar tissue was very marked on the inner side, where it extended beyond the internal condyle.

vOL. LXXII. 
The outer surfaces of the upper arm, elbow, and forearm were free from scar tissue.

On July 14th the first stage of the operation was performed. A strap or bridge of skin was raised from the outer side of the upper and forearms with the intention of transplanting it obliquely across the front of the elbowjoint. It was eight inches in length and two and a half to three inches in width. Its centre was opposite the flexure of the elbow-joint. It was dressed and treated in the usual manner.

On the seventeenth day transplantation was accomplished. The web was cut completely across. This transverse incision was crossed by a short vertical one on the inner side, and the edges were dissected up until they formed fringes. Next the lower end of the bridge was severed, the edges and under surface for about one half of its length were pared, and then the flap was sutured into place. The distal half fitted accurately into the wound, but, as in the other cases, the lower edge of the proximal half could not be sutured at all. The end and edges united by primary union, and no sloughing occurred in that part of the transplant.

About half way along the lower edge a small slough happened, and that of course reduced the width of the flap in that situation.

Healing went on very satisfactorily, and in the middle of August she was able to bear to have an extension apparatus applied.

On October 19th she left the hospital for her home. The arm then was in a very improving and promising condition.

CASE 5.-Emma W-, æt. 9, admitted January 13th, 1887. Badly burnt when two years of age (seven years ago) over right side and front of neck from below ear and chin down to the clavicle and left sterno-clavicular joint. The left side was not so extensively burnt as the right.

On admission she was observed to be rather short for nine years of age and not strong.

The deformity of the mouth and neck, in consequence of 
the contraction of the cicatrix of the burn, was very marked and unsightly.

The right angle of the mouth and lower lip were drawn downwards and to the right side, so that the front lower teeth were exposed and inclined forwards and to the right. Saliva and mucus dribbled away, and it was only by a determined effort that she could keep her mouth closed.

The right side of the face was drawn down, and the right lower lid slightly everted. The chin was effaced, and the head, particularly on the right side, was tightly drawn down towards the clavicle and shoulders.

On the sides and front of the neck the scar tissue had become drawn into dense tight bands or fræna, which could be taken between the thumb and finger. There were four primary bands, one on the right side from the angle of the jaw to the clavicle, one on either side of the middle line, and a fourth on the left side. The greatest amount of contraction was from the symphysis of the jaw to the suprasternal notch.

First operation (February 26th, 1887).-A bridge of skin was raised from the side of the neck and shoulder eight inches long by nearly two inches and a half wide. The fat layer beneath the integument was thin. The fibres of the trapezius and deltoid were exposed. This was dressed in the usual manner. Retentive bandages were applied, but no rigid apparatus was put on for the purpose of preventing movements of the head and neck, as it was thought that the natural instincts of the patient would aid to prevent tension of the flap. However, in ten days' time I observed that the whole strap had narrowed, and that the central part of the strap, for nearly two inches, was thinning both in thickness and width. I attributed this partly to deficient general power and partly to mobility and tension of the flap. I therefore had an apparatus made in order to fix the head over to the right side. Mr. Ernst rapidly carried out this design. The ulceration was arrested in the strap, and when it became evident that no further improvement would take place in the nutrition of the whole strap, 
on March 21st, or twenty-three days after the first operation, I performed the second.

An incision was made across the contracted scar from right to left, rather nearer the lower jaw than the clavicle. The upper and lower edges were raised, so that they formed fringes about an inch deep. Into this wound I transplanted the strap about seven inches long, or three times the width of the base, fixing the free end carefully by sutures, and suturing the whole length of the upper border and the anterior half of the lower border. The wound was dressed in the usual way.

No ulceration or sloughing took place. Good union followed between the free end of the flap and surrounding parts.

The sore on the shoulder healed slowly, and the child was rather weakly.

On May 15th she was sufficiently well to leave the hospital, as the sore on the shoulder had very nearly healed.

Readmitted June 28th. Transplant very healthy and stretching. Spots in the shoulder scar had reopened from friction or deficient nursing at home. She was able to leave in a month's time, on July 27th.

Readmitted October 21st same year, for sores on shoulder. She was kept in until December 14th, when she was again well enough to be discharged.

At this time the vertical scar to the right of the middle line showed a tendency to contract, and although the transplant stretched, considerable contracture remained at the side of the neck. Only a partial success. The transplant had not been long enough to reach across the middle line, as it had been originally designed to do.

May 14th.-The child remains under treatment; no further operation has been done.

July, 1889.-Improvement continues.

After the paper had been read, the patients were severally shown to the Society.

(For report of the discussion on this paper, see ' Proceedings of the Royal Medical and Chirurgical Society,' Third Series, vol. i, p. 124.) 